\title{
Internet, governo e cidadania
}

Henrique Flávio Rodrigues da Silveira

Mestrando em Ciência da Informação (UnB). Analista do Banco Central do Brasil, com atuação na área de planejamento. Formado em processamento de dados pela Universidade Federal do Ceará (1986), com cursos de especialização (lato sensu) em informática (1989) e marketing (1994).

henrique.silveira@bcb.gov.br

\section{Resumo}

O trabalho apresenta algumas reflexões sobre a utilização da Internet para ações do governo brasileiro, nas áreas de comunicação e prestação de serviços, e o exercício da cidadania. Trata-se de questão complexa, pois envolve tanto aspectos físicos quanto sociais. O "apartheid digital" alerta para a diferenciação entre os cidadãos brasileiros no acesso aos serviços e informações. São apresentadas observações sobre o processo de construção de sítios por parte das organizações públicas. Destaca a necessidade de se desenvolver um modelo mais cooperativo e menos corporativo que facilite a recuperação de informações. Finalmente, o trabalho tece algumas considerações sobre a responsabilidade de o governo evitar que a nova era agrave os desequilíbrios atualmente existentes na sociedade brasileira e garantir a todos igual oportunidade de acesso aos recursos de informação.

\section{Palavras-chave}

Governo; Cidadania; Informação; Exclusão digital.

\section{Internet, government and citizenship}

\begin{abstract}
This paper presents some reflections about the use of Internet as means for carrying out actions by the Brazilian government in the areas of communication and rendering of services, as well as the improvement of the conditions of living of the citizens. It is a complex subject, because it involves both physical and social aspects. The "digital apartheid" points out the disparity among the Brazilian citizens as to the access to the services and information. Observations are made about the process of building sites by public organizations, and the need to develop a more cooperative and less corporate model is emphasized, what would make it easier to retrieve information. Finally, the paper presents some considerations about the government's responsibility in order to prevent the new era from making worse the disparity already existing in the Brazilian society, and to guarantee, for everyone, equal opportunity of access to information resources.
\end{abstract}

\section{INTRODUÇÃO}

Este trabalho apresenta algumas reflexões sobre a utilização da Internet para ações do governo brasileiro, nas áreas de comunicação e prestação de serviços, e o exercício da cidadania. Inicialmente são destacados aspectos relativos às iniciativas do governo para democratizar o acesso aos novos serviços, notadamente por meio do Programa Sociedade da Informação. Trata-se de questão complexa, pois envolve desde aspectos físicos (a partir da construção da infra-estrutura) até aspectos sociais (capacitação, entre outros) e culturais (como a preservação dos valores e culturas locais). É também apontada a necessidade, já percebida e com ação de governo a respeito, de otimização da utilização da rede de telecomunicações pelos órgãos públicos.

A seguir, são apresentadas algumas questões que levam à reflexão sobre como determinadas ações do governo e de empresas, nas áreas de comunicação e prestação de serviços, estão diferenciando os brasileiros entre os que têm acesso à Internet e os que não têm, sem que a correspondente possibilidade de acesso esteja ao alcance de todos, independentemente do poder aquisitivo ou nível de instrução. É o "apartheid digital", de que trata o documento de lançamento do Programa Sociedade da Informação (1999). A injusta distribuição da riqueza nacional não deveria se repetir no acesso à informação e aos serviços públicos.

O trabalho ainda aponta outra necessidade a ser incrementada como ação de governo. Trata-se da construção de portais cooperativos entre órgãos públicos que permitam aos cidadãos o acesso a bases cooperativas de informações, obtendo, em um mesmo portal, informações provenientes de diversos órgãos públicos. Referidos portais evitariam (ou minimizariam) a "navegação" isolada e a posterior consolidação de informações, facilitando a vida dos que precisam de informações públicas. São também apresentadas algumas considerações sobre a construção de sítios por parte de organizações públicas - o processo de desenvolvimento, de gerência e as peculiaridades em relação aos sítios privados.

\section{Keywords}

Government; Citizenship; Information; Digital exclusion. 
Finalmente, o trabalho apresenta algumas ponderações sobre a responsabilidade do governo como único agente capaz de evitar que a nova era agrave os desequilíbrios sociais e regionais hoje existentes e de assegurar o efetivo exercício da cidadania, garantindo a todos tratamento igual em termos de oportunidades básicas de acesso aos recursos informacionais, resultando a diferenciação a partir da capacidade, do talento e dos esforços individuais.

\section{O GOVERNO E A INTERNET}

O Programa Sociedade da Informação, lançado em 1999 pelo governo federal, pretende estabelecer as bases para uma inserção competitiva do Brasil na sociedade global da informação e tem por finalidade integrar e coordenar o desenvolvimento e a atualização de serviços avançados de computação, comunicação e informação e suas aplicações. O programa também pretende estimular a pesquisa e a educação, assegurando que o Brasil tenha condições de competir no mercado mundial.

Segundo o documento de lançamento do programa, é necessário que o Brasil adote uma política interna e externa "pragmática e ágil", se pretende lograr êxito em empreitada de tamanha complexidade. $\mathrm{O}$ documento também reconhece que, no Brasil e em todo o mundo, parte das desigualdades entre pessoas e instituições é resultado da "assimetria no acesso e entendimento da informação" disponível, o que define a capacidade de agir e reagir de forma a usufruir seus benefícios.

Com a crescente importância da tecnologia da informação na vida em sociedade, a referida assimetria tende a se fazer progressivamente mais sentida, agravando o apartheid social. Daí a decisão de governo de intervir no processo. Na chamada "primeira fase" da Internet, o governo federal teve participação decisiva, por meio da Rede Nacional de Pesquisa (RNP). Foi a RNP que, a partir de 1989, com o propósito de conectar os pesquisadores brasileiros aos seus pares no exterior, viabilizou a entrada do Brasil no novo ambiente de comunicação e informação.

Com a liberação do uso da Internet para fins comerciais (que no Brasil ocorreu em 1995), tornou-se claro que a Web não seria apenas mais um lugar para se "fazer as mesmas velhas coisas de modo um pouquinho diferente" (Nóbrega, 1999), e, desde então, a Internet vem impactando, ano após ano, as estratégias de empresas, organizações não-governamentais e governos. Em 1994, o número de usuários da Internet no Brasil situava-se em torno de 36 mil pessoas, todas no meio acadêmico. No final de 1999, o número já chegava a 3,6 milhões (100 vezes mais) (Gurovitz, 1999). Embora esse número represente apenas 2,5\% da população brasileira, e persistam graves desigualdades de renda, desníveis sociais e regionais, o Brasil apresenta efetivas condições de desenvolvimento e utilização dos recursos da Internet e, também, busca um espaço para competir na denominada Nova Economia.

Desde o projeto original - Arpanet -, patrocinado pelo Departamento de Defesa dos Estados Unidos, como objetivo de criar uma rede com arquitetura flexível o suficiente para não depender de nós centrais e que, por isso, pudesse continuar em operação caso alguns dos computadores principais deixassem de funcionar, a Internet percorreu um longo caminho, inicialmente concentrando-se no meio acadêmico.

Um novo caminho para a Rede começou a partir dos conceitos de hipertexto e hipermídia, que constituem a base da interface gráfica da Internet, mais conhecida como WWW (world wide web, ou simplesmente Web). A Web nasceu em 1990, com a criação da linguagem HTML (hypertext markup language) por Tim Berners-Lee, com a finalidade de interligar os computadores em um laboratório de física (Monteiro, 2000).

Com os recursos proporcionados pela linguagem HTML, o uso da Internet passou a intensificar-se fora do meio acadêmico. Mas foi a incorporação de recursos multimídia (texto, imagem e som), por meio de um visualizador gráfico para acesso à Web, que popularizou definitivamente a Internet: em 1993, Marc Andreessen desenvolveu o Mosaic, que inspirou os sucessores Navigator e Explorer.

O desenvolvimento da Web possibilitou que a Internet alcançasse, em um período de cinco anos, a marca de 50 milhões de usuários em todo o mundo, marca atingida pelo rádio em 38 anos, pela televisão "aberta" em 16 anos e pela televisão por assinatura em 10 anos (revista Diga lá, 1999). Mais importante, porém, pode ser a intensidade com que a tecnologia dos computadores exigiu a adaptação das pessoas e das organizações (Dizard, 1982), em comparação com a forma gradativa de outras revoluções tecnológicas. Castells (1999) registra que a Internet foi "apropriada" por pessoas e organizações com os mais diferentes objetivos.

A "explosão de informações" provocada pela massificação do uso da Internet, com a multiplicação de páginas pessoais, institucionais e comerciais (identificadas por um nome único, conhecido como Uniform Resource Locator - URL), trouxe um desafio excepcional para os profissionais de informação: a adaptação do processo de 
recuperação de informação (indexação, armazenamento e recuperação) a esse novo ambiente (Teixeira, 1997). Parte dessa necessidade foi suprida pelo desenvolvimento de ferramentas de busca a partir de empresas independentes, que passaram a catalogar os endereços, indexando-os e agrupando-os, visando à recuperação via Web.

A questão é complexa, pois as organizações precisam lidar com esse novo ambiente, e os métodos de intercomunicação praticados devem acompanhar o ritmo de produção e consumo de informação (Maloff, 1996). Deve ser percebido o valor da Internet como parte estratégica no processo de posicionamento competitivo, e não apenas como mais uma "modernidade".

Deve-se ter em mente que a Internet não é apenas uma nova interface para os antigos sistemas de recuperação de informação. Junto com a Internet, foram desenvolvidas novas tecnologias, impactando a velocidade de transmissão e de processamento e a conectividade de equipamentos. Em termos de software, novos programas permitem interfaces mais amigáveis e personalizáveis, além de sistemas gerenciadores de bancos de dados com mais recursos e melhor performance.

As novas tecnologias (de hardware e de software) tornaram viável a construção de sistemas de recuperação de informação utilizando interfaces gráficas que aproximam o sistema do usuário, aumentando a facilidade de uso e a participação do sistema nos processos decisórios das organizações. É comum a criação de interfaces que simulem o cotidiano do usuário, o que contribui para a quebra de barreiras com relação à tecnologia (Teixeira, 1997).

Em relação ao tema deste trabalho - Internet, Governo e Cidadania -, o esforço de inclusão do país na nova era se insere no âmbito da Reforma do Estado, levada a efeito a partir do primeiro mandato do presidente Fernando Henrique Cardoso. A reforma tem, entre seus pressupostos, a existência de mecanismos de controle dos organismos estatais por parte da sociedade.

Conforme Pereira (1997), o princípio geral "é o de que será preferível o mecanismo de controle que for mais geral, mais difuso, mais automático", o que é perfeitamente compatível com os fundamentos da Internet. Beniger (1986) também afirma que o controle de qualquer "sistema" está relacionado ao processamento distribuído ao acesso generalizado.
Nesse sentido, o referido programa apresenta, como um dos objetivos setoriais, o desenvolvimento de sistemas para integrar e ampliar ações de governo em benefício da cidadania, no novo "paradigma da sociedade da informação". Os conteúdos disponibilizados pelos governos (federal, estadual e municipal) devem, progressivamente, facilitar o exercício da cidadania.

Segundo o documento de apresentação do programa (1999), existem três tipos de presença de organizações públicas na Internet:

a) oferecimento apenas de informações institucionais;

b) prestação de serviços relevantes de download (cópia a partir de um computador remoto) de informações para o usuário;

c) prestação de serviços públicos em tempo real e de forma interativa com o cidadão.

A busca, por oferecer maior possibilidade de controle e transparência, não se constitui, entretanto, na única motivação do governo para oferecer serviços e informações via Internet. Em tempos de recursos públicos escassos e uma demanda crescente da sociedade, a possibilidade de aumentar o atendimento à sociedade sem o correspondente incremento nos recursos historicamente alocados para esse fim - pessoal, instalações e equipamentos impulsiona e alimenta o esforço do governo.

O custo de transações via Internet, de fato, é bastante reduzido em relação ao custo daquelas realizadas por meios tradicionais. $\mathrm{O}$ uso comercial da Internet reduz os custos das comunicações telefônicas em 95\%, os de fax em 35\% e os das transações bancárias em 50\%. Para os bancos, especificamente, o custo de uma transação via Internet é de US $\$ 0,13$, enquanto as realizadas em caixas eletrônicas saem por US\$0,27 e as realizadas na agência custam US\$1,00 (Diga lá, 1999).

Outros custos, porém, são alvo das atenções do governo. Segundo a Agência Nacional de Telecomunicações (Anatel), a multiplicidade de redes de telecomunicações mantidas pelos diversos órgãos de governo, distribuídos nas diferentes esferas dos poderes Executivo, Legislativo e Judiciário, gera custos que poderiam ser reduzidos, se houvesse maior integração entre as redes. Além dos custos financeiros, há a questão da racionalização e integração das ações de governo, que gera custos e desperdícios difíceis de mensurar. Seria preciso utilizar, de forma mais eficiente e de modo exemplar, a infra-estrutura de telecomunicações, essencial para que o governo desenvolva suas atividades finalísticas. 
Assim, o governo utiliza a Internet como instrumento de aproximação com a sociedade - por meio da prestação de serviços e disponibilização de informações - ao mesmo tempo em que amplia sua capacidade operacional e sua área de cobertura. $\mathrm{O}$ desempenho da burocracia estatal deve ser melhorado, então, pela otimização dos processos e diversificação dos meios para prestação de serviços. Essa melhoria não pode acontecer sem modernas tecnologias de criar, gravar, armazenar e processar informações (Beniger, 1986).

\section{QUESTÕES PARA REFLEXÃO}

\section{Caso 1}

A Receita Federal mantém um sítio que recebeu quatro prêmios da edição 2000 do iBest: categorias Governo e Serviços Públicos, conferidos pelos júris oficial popular. Entre os serviços oferecidos, o sistema de recepção de declarações de imposto de renda pela Internet é modelo para muitos países e alcançou em 2000 a fantástica marca de 10 milhões de declarações. O sistema apresenta uma série de vantagens em relação aos formulários em papel, em termos de racionalização do processo, níveis de confiabilidade e segurança, quantidade de pessoal envolvido e custos incorridos. Para incrementar a utilização da Internet, a Receita Federal confere prioridade à restituição das declarações entregues via Internet, fazendo com que os contribuintes que entregaram as suas declarações em papel sejam postos no "fim da fila", sob o argumento de que têm de ser submetidos à digitação, conferência e processamento - o que é verdade. Entendese a preocupação da Receita Federal em aperfeiçoar o processo de recepção e tratamento das declarações, e o sucesso do modelo pode ser aferido pelo crescimento exponencial do número de contribuintes que utilizaram a Internet - claro que o novo sistema também traz vantagens para o contribuinte (tempo, segurança, comodidade). Mas há contribuintes que cumpriram suas obrigações com o fisco, entregaram suas declarações no prazo - talvez até no início do prazo - e utilizaram-se do "antiquado" mecanismo conhecido como "formulário". Por que eles têm de ser discriminados apenas por não terem acesso aos recursos da moderna tecnologia? Afinal, apenas 2,5\% dos brasileiros têm computador (Gurovitz, 1999), e não há programas implantados de quiosques públicos para acesso à rede - pelo menos não na quantidade que possibilite $o$ acesso potencial dos "sem-tecnologia", sem contar a necessidade de um mínimo de treinamento para utilização. A isonomia de tratamento entre os contribuintes em uma mesma situação (ressalte-se: situação perante o fisco, não perante a tecnologia) não está sendo observada.
O caso da Receita Federal é emblemático das contradições que envolvem o discurso e a prática em um país tão heterogêneo como o Brasil. Sobram razões para imaginar que o sucesso da entrega de declarações de renda pela Internet deve-se, em boa parte, à prioridade no momento da devolução. A possibilidade de receber a "ajuda" do programa para preenchimento do formulário eletrônico (aproveitamento de dados do ano anterior, cálculos, simulações, conferências etc.) responde pelo restante das adesões à declaração pela rede.

Mesmo admitindo que uma parte (não mensurada) das declarações foi enviada por escritórios que fizeram esse serviço para os contribuintes, restaria uma quantidade enorme de brasileiros que resolveu "encarar" o computador para o encontro de contas com a Receita em 2000 - muitos certamente com a ajuda de filhos, parentes e amigos. Reportagens mostraram que, mesmo sem acesso a computador conectado à rede em casa ou no trabalho $\mathrm{e}$ sem recorrer a escritórios especializados, muitos contribuintes resolveram, assim mesmo, usar a Internet e fizeram, portanto, a alegria dos cibercafés.

Essa aproximação com a tecnologia certamente trouxe benefícios para os contribuintes - sem contar, é claro, os benefícios para a Receita Federal, dos quais destacamos a redução de custos e a racionalização do processamento. Para muitos contribuintes, foram abertas as portas da Internet, o que pode representar a possibilidade de acesso a informações úteis para a vida pessoal e profissional. Para as empresas, o aumento de empregados com conhecimento básico de microinformática e acesso à rede pode implicar aumento de produtividade, que compense, com larga margem, o custo do tempo e dos equipamentos colocados à disposição dos empregados para seus acertos de contas com o fisco.

Os "sem-tecnologia", entretanto, também têm seus motivos para não aderir: desconhecimento de como utilizar o computador, falta de acesso (em casa ou no trabalho) e até uma certa dose de desconfiança em transmitir seus dados pessoais pela rede (embora seja muito mais seguro que entregar o formulário em papel, que circulará por várias áreas e em mãos de várias pessoas até se tornar um formulário eletrônico!). A Receita e os bancos credenciados para recepção das declarações chegaram a disponibilizar equipamentos, mas apenas para transmissão das declarações, que já deveriam estar previamente gravadas em disquete, permanecendo a questão do acesso ou familiaridade com a tecnologia, para gravação da declaração e geração do disquete. 
Resta a questão para reflexão: ao privilegiar os contribuintes "internautas", a Receita Federal otimizou o serviço e prestou um serviço ao país com o estímulo extra à "internetização", mas como fica a situação dos que não têm acesso ou habilidade para usar a tecnologia disponibilizada? Não há nenhum programa oficial, de caráter nacional, que permita o acesso e forneça capacitação para uso do computador e da Internet, embora o Programa "Sociedade da Informação" acene com projetos nesse sentido. Rui Barbosa dizia que o governo devia "tratar desigualmente os desiguais", obviamente referindo-se à responsabilidade do governo em atuar na redução das desigualdades de oportunidade das pessoas. No caso da Receita, o governo agiu no sentido contrário, acentuando a desigualdade, ao estimular e "premiar" quem acessa a moderna tecnologia e "punir" quem não a usufrui.

\section{Caso 2}

As empresas de telecomunicações, recém-privatizadas, mas que permanecem concessionárias de um serviço público, vêm promovendo ampla reformulação na sua política de atendimento ao público. As empresas vêm investindo em atendimento por telefone e pela Internet, em vez das tradicionais lojas com atendimento pessoal, que são fechadas ou drasticamente reduzidas em capacidade de atendimento e cobertura geográfica. As empresas argumentam que precisam reduzir custos e melhorar o atendimento, oferecendo maior comodidade aos clientes, que podem (tentar) resolver seus problemas sem precisarem se deslocar até às (antigas) lojas de atendimento pessoal. Dessa forma, os usuários que têm acesso à Internet conseguem registrar e (talvez) até receber respostas aos seus questionamentos, enquanto os que fazem uso do telefone (dos outros ou público, em caso de pane) devem cumprir um roteiro menos confortável para solucionar seus problemas. Problema mesmo têm aqueles usuários que não têm acesso à Internet e não têm tanta flexibilidade para usar os telefones dos outros ou a rede de telefones públicos, pois são encaminhados a uma loja de atendimento pessoal com estrutura tão "enxuta”, que parece convidar os usuários a não utilizar mais os seus serviços. Convém registrar que os usuários que aderiram à tecnologia e comodidade, vez por outra, deverão fazer companhia aos "sem-tecnologia", pois alguns serviços ou esclarecimentos só podem ser prestados pela antiga forma do atendimento pessoal.

As alterações na estrutura das empresas de telecomunicações (e poderia ter sido utilizado o caso das concessionárias de energia elétrica já privatizadas, como também o caso dos bancos) devem-se, segundo as empresas, à necessidade de promover ajustes e modernizações que se refletirão na qualidade e no preço dos serviços. A Agência Nacional de Telecomunicações (Anatel), como órgão regulador, tem como um dos fatores de avaliação das empresas concessionárias a qualidade do atendimento, o que pode ser representado pelo volume de reclamações e pela presteza na solução de problemas. Mas, e a questão da democratização no acesso ao serviço de atendimento?

O maior acesso à telefonia propiciou a milhões de brasileiros a oportunidade de romper a barreira das telecomunicações, mas a barreira do efetivo exercício da cidadania ainda é representada pela dificuldade de acesso à tecnologia, quando ela se torna o veículo, embora não exclusivo, de reivindicação de direitos. Reduzir o atendimento pessoal, ao qual todos têm acesso, e oferecer como alternativa (embora não exclusiva, pois há o atendimento telefônico) a Internet, à qual poucos têm acesso, passa uma idéia de modernidade que não se sustenta na realidade da maioria dos usuários, que não tem acesso à rede.

A Anatel, com certeza, está atenta para esse problema, que somente encontrará solução com a intervenção do governo como agente regulador, pois as conhecidas "forças do mercado" atuarão, permanentemente, no sentido de disponibilizar soluções de negócio que privilegiem a redução de custos, a maximização dos lucros e a interatividade com os clientes a partir de plataformas virtuais.

\section{Caso 3}

A Previdência Social vem promovendo inovações no atendimento aos contribuintes e beneficiários. Convivendo com escassos recursos, a Previdência Social vem aumentando sua presença em todo o território nacional e aproximando-se dos seus usuários, por meio da utilização de postos volantes, de atendimento por telefone, de convênios com estados, prefeituras, empresas e a prestação de alguns serviços pela Empresa Brasileira de Correios e Telégrafos (ECT). Outro meio que vem recebendo atenção é a utilização da Internet, por meio da qual os contribuintes ou beneficiários podem obter diversas informações, e até a emissão de certidões negativas. Tratase de uma alternativa com grande potencial de crescimento, que de fato reduz custos para a Previdência e traz vantagens para os usuários, em termos de tempo e comodidade. Mas a maioria dos beneficiários e uma parte não desprezível dos contribuintes (basicamente pessoas físicas e pequenas empresas) não têm acesso à Internet ou familiaridade com a moderna tecnologia e têm de 
continuar buscando o atendimento pessoal. Apesar do esforço para melhorar a qualidade do atendimento nos postos, como algumas modificações já implantadas sistema de senhas e cadeiras de espera -, há constantes registros de demora. É certo que a Previdência não discrimina intencionalmente os usuários - ela apenas oferece mais uma forma de prestação de serviços, mas o fato é que quem tem acesso à Internet (em regra usuários mais bem situados na estrutura social) são "melhor atendidos" (as aspas são para denotar que não há intenção prévia de discriminar) do que aqueles que não dominam as artes da moderna tecnologia.

O caso da Previdência Social é diferente do caso da Receita Federal, pois não há tratamento diferenciado explícito entre os usuários que acessam os serviços via Internet e aqueles que procuram os postos de atendimento, a não ser, é claro, a tempestividade na obtenção da informação ou do documento desejado, se admitirmos que a qualidade seja a mesma. O estímulo se dá por meio da oferta de um melhor serviço, sem estabelecer outros "prêmios" por sua utilização. O esforço da Previdência em dotar suas agências de máquinas de auto-atendimento é uma tentativa de concretizar a oferta da nova plataforma tecnológica para usuários sem acesso à Internet, mas que também precisa vencer a barreira do treinamento e familiaridade com máquinas, computadores e outras "engenhocas".

Outros órgãos públicos, nas várias esferas de governo, já disponibilizam serviços via Internet ou pretendem fazêlo em breve. Administrar a convivência entre o atendimento convencional - que pode de deve ser melhorado devido à tecnologia - e a nova modalidade de atendimento eletrônico (ou virtual), garantindo a igualdade de oportunidades de acesso ao que é público, constitui a equação gerencial a ser resolvida.

\section{PORTAIS COOPERATIVOS E PRESENÇA DO SETOR PÚBLICO NA INTERNET}

Os sítios governamentais, especificamente os do governo federal, constituem-se em um imenso arquipélago, formado por ilhas (sítios), que não se comunicam entre si. O que existe são pontes virtuais entre as ilhas, o que possibilita ao usuário navegar entre elas, mas, se ele porventura precisar de informações que estão distribuídas, caberá a ele, usuário, a tarefa de reunir e tentar padronizar o conjunto de informações coletadas. Ou seja, o que existe hoje são portais corporativos, com administração individualizada, que até oferecem a possibilidade de acesso a outros sítios ou portais, mas entendemos que o usuário precisa dispor de portais cooperativos no setor público.
Portais cooperativos seriam portais que envolveriam, em seu desenvolvimento e gerência, a participação de várias organizações públicas. $\mathrm{O}$ usuário acessaria, a partir de um determinado sítio, um conjunto de informações e serviços de origem variada, sem a utilização de ligações (links) entre os sítios originais dessas organizações.

Na sua revista de maio/junho-2000, o Serpro - empresa do Ministério da Fazenda, apresenta o "c-brazil.com", uma espécie de portal "cooperativo" do comércio exterior do Brasil. A iniciativa conta com a participação inicial de vários órgãos do governo ligados ao assunto (Ministério do Desenvolvimento, Indústria e Comércio, Ministério das Relações Exteriores, Secretaria da Receita Federal e Banco Central) e está sendo conduzido a partir de uma parceria do Serpro com empresas privadas. O portal pretende oferecer um conjunto de serviços gratuitos e um conjunto de serviços tarifados, que responderá pela autosustentabilidade do empreendimento.

Em um ambiente em permanente mutação, as organizações buscam, cada vez mais, exercitar a função administrativa de cooperação (Kira, 1994). Segundo a autora, o avanço das tecnologias e das telecomunicações tornaram a "racionalidade de esforços" algo passível de implementação. Convênios para ações cooperativas previstas por Cunha (1999) para bibliotecas poderão se tornar usuais entre organizações públicas. Nesse sentido, a proposta inovadora do Serpro deve ser estudada e pode inspirar algo semelhante em termos de informações e serviços públicos, mais afetos ao exercício da cidadania de forma geral do que dirigidos a segmentos específicos da sociedade, como os agentes envolvidos com comércio exterior.

As organizações públicas que já estão ofertando informações e serviços pela Internet desenvolveram um conhecimento que será bastante útil quando os portais corporativos forem desenvolvidos. Passamos a seguir a apresentar algumas considerações sobre o processo de construção de sítios com oferta de produtos e serviços públicos pela Internet.

O planejamento de sítios em organizações públicas deve incorporar a busca pelo interesse e necessidades dos cidadãos, e não apenas a redução de custo por transação. Jardim (1999) ainda ressalva que as organizações públicas devem ir além da disponibilização de um simples folder eletrônico. 
Entre as características do novo ambiente, está a evolução do desenvolvimento de interfaces para busca de informações, que passou de um processo que exigia a intermediação para um ambiente de acesso universal (Marchionini, 1998), no qual os usuários nem sempre possuem experiência ou treinamento. Ainda em 1977, Miranda registrava que o usuário dos sistemas de informação deveria ser "qualquer indivíduo, em qualquer nível da atividade humana".

Fleming (1998) sugere que as organizações devem definir perfis de usuários, de acordo com os produtos e serviços oferecidos, e pensar o sítio de forma a atender aos diferentes perfis construídos a partir de observação ou reuniões com grupos de usuários, alternativa também defendida por Nielsen (2000). Uma outra possibilidade, ainda segundo a autora, é a utilização de cenários, que podem oferecer uma visão do processo navegacional como um todo. Pensar em cenários também ajusta a visão de um sítio como um espaço ativo para pessoas que se movem ao seu redor.

A página inicial (home page) de uma organização pública deve incluir dados para contato na forma convencional (telefone, fax e endereço), além de uma ligação para correio eletrônico (e-mail). A inclusão de dados para comunicação na forma convencional é relevante para possibilitar que usuários que tenham acesso ao sítio, on-line ou por meio de cópia impressa e precisem utilizar meios que não o correio eletrônico, possam continuar o processo de comunicação com a organização.

Os produtos e serviços devem ser oferecidos em uma linguagem impecável, sem erros gramaticais ou tipográficos (letras trocadas, repetição de palavras etc.). Em sítios de organizações públicas também não é recomendável a utilização de gírias ou regionalismos (a não ser em instituições de caráter regional), bem como anglicismos, dispensáveis no caso de existência de equivalente em língua portuguesa. Há países c5omo a França, por exemplo, que utiliza um "Dicionário de Termos Oficiais” em relação ao vocabulário da Internet. Informalidades podem refletir amadorismo e devem ser evitadas pelo risco de comprometer a credibilidade (Nielsen, 2000).

Vickery (1989) alerta que, mesmo em uma comunidade que fala a mesma língua, existem barreiras para a compreensão, em função da variação no tamanho e riqueza do vocabulário das pessoas. Textos escritos de forma direta, com sentenças curtas e sem rebuscamentos estilísticos devem ser preferidos.
A interação, a coesão, entre a arquitetura (estrutura lógica) e a interface (parte visual) é importante para que os usuários consigam extrair do sítio a satisfação de suas necessidades (Fleming, 1998). A interface representa a intermediação entre os usuários e o conteúdo do sítio. Ainda segundo Fleming, a interface é um interpretador e guia para as complexidades do sítio. Nielsen (2000) afirma que a arquitetura de informação a ser aplicada não deve, necessariamente, refletir a forma como a organização está estruturada hierarquicamente, e sim espelhar as necessidades dos usuários e suas visões do espaço informacional.

Sobre arquitetura de informação, Rosenfeld (1998) afirma que ela envolve o design de organização, rotulagem, navegação e sistemas de busca para ajudar as pessoas a encontrar e gerenciar informação de uma maneira mais eficiente. Sucintamente, arquitetura de informação tem a ver com o entendimento e a condução e deve ser definida antes da construção do sítio.

A respeito do uso intensivo de novas tecnologias, Valle (2000) comenta sobre os cuidados que as organizações devem tomar, tendo em vista o impacto que podem causar à navegação. A opção deve ser por sítios funcionais, que utilizem apenas tecnologias que de fato agreguem valor para o usuário, e não sejam empregadas apenas para demonstrar modernidade e aumentar os custos. Nielsen (2000) também alerta que devem ser evitados "leiautes densos, carregados".

As organizações não devem esquecer, também, que não há controle sobre as especificações dos equipamentos dos usuários, e "incrementar" sítios pode tornar-se uma fórmula perfeita para afugentar os usuários que não dispõem de equipamentos de última geração (Nielsen, 2000). Nesse sentido, Nielsen sugere que sejam utilizadas apenas tecnologias consolidadas e tidas como "padrões".

A atualização é um fator de credibilidade para o sítio. A preocupação com a atualização pode ajudar a conquistar a confiança do usuário, e os itens atualizados podem ser objeto de destaque, nos casos em que há relevância no alerta para quem acessa o sítio. As ligações para páginas externas devem ser periodicamente testadas, para evitar que o usuário seja frustrado ao tentar o acesso a partir de página da organização.

Estabelecer mecanismos de acompanhamento da utilização do sítio pode render bons frutos. Manter-se em permanente vigília sobre as necessidades dos usuários, por meio da observação ou de grupos de usuários (o uso de grupos focais pode ser uma alternativa), proporciona um feedback capaz de manter o sítio atraente e funcional. 
Caso a organização também utilize Intranet e Extranet, deve ser observado que os públicos esperados nesses casos têm objetivos e expectativas diferentes dos usuários da Internet. Além das motivações dos usuários, deve ser considerado que na Intranet são conhecidos os equipamentos dos usuários, o que pode facilitar a padronização e utilização de tecnologias, o que não acontece na Internet.

$\mathrm{Na}$ Extranet (extensão da Intranet para incorporar usuários externos selecionados - Nielsen, 2000), talvez não seja possível estabelecer algum padrão para os equipamentos, e, exceto pela questão da segurança, o trabalho de construção aproxima-se mais daquele realizado na Internet que na Intranet.

Embora a possibilidade de aumentar a presença e visibilidade da organização pública sem um aumento de custos equivalente à forma tradicional de expansão (instalações, pessoal etc.), deve ser mais importante o alcance dos benefícios para os usuários que a simples redução de custos, embora ambos sejam desejáveis (Maloff, 1996). Como em outros produtos e serviços, a definição de uma política de cobrança pode ser aplicável.

A organização pública que oferta produtos e serviços pela Internet precisa divulgar essa nova modalidade de interação com a sociedade. A estratégia de divulgação dos produtos e serviços ofertados deve incluir a presença em outros sítios e na mídia convencional, com a divulgação do endereço eletrônico. A inclusão de ligações (links) em outros sítios governamentais e a autorização para sua utilização em sítios privados pode ampliar a visibilidade da organização. $\mathrm{Na}$ área governamental, a relação pode ser hierárquica ou temática, e deve ser buscada, sempre que possível, uma integração entre os conteúdos, facilitando o processo de busca realizado pelos usuários.

Em sítios privados, a relação deve acontecer pela possibilidade de utilização por parte do usuário, como, por exemplo, no caso de sítios sobre finanças e economia, que poderiam incluir ligações (links) para organizações públicas responsáveis por índices de preços e desemprego.

Em suma, as organizações públicas precisam estar presentes na Internet, por meio de sítios que apresentem um conteúdo bem relacionado, uma arquitetura funcional e um design atraente, que ofereça uma navegação objetiva e sem "armadilhas". Mas não devem esquecer os milhões de cidadãos para os quais o acesso à Internet ainda não é uma realidade cotidiana, não existem programas de financiamento público para aquisição de computadores em larga escala, do tipo anunciado pelo governo argentino, que pretende financiar um milhão de computadores (Newsletter, 2000).

Mesmo em países desenvolvidos, como a Inglaterra, um estudo da Bozz-Allen\&Hamilton Brasil, apresentado durante o seminário "Estado Democrático e Governança no Século XXI" (31 de maio a 2 de junho de 2000, em Brasília), mostra que 40\% dos cidadãos ingleses ainda não têm acesso universal assegurado - isso no país (Inglaterra) que tem o mais alto índice de assinantes europeus. O mesmo estudo confirma a já referida "assimetria" entre as faixas de renda e o acesso à Rede: apenas $7 \%$ dos usuários da Rede são da faixa de renda mais baixa.

\section{A RESPONSABILIDADE DO GOVERNO}

Em 1994, durante o lançamento do projeto "NII" (Internet II), o governo americano anunciou que, "se é para a NII ser uma ferramenta de melhoria de vida de todos os americanos, todos os americanos devem ter acesso aos atributos e capacidades da NII" (Sullivan-Trainor, 1995). No mesmo documento, o governo americano ainda afirma que, para atingir a meta de acesso universal, "algum nível de subsídio será inevitável”.

No Brasil, o Programa "Sociedade da Informação", conforme já apresentado, é uma demonstração clara da consciência do governo de que a intervenção no mercado, mediante parcerias e projetos estruturadores, é a única forma de buscar uma inserção competitiva do país no cenário internacional. Castells (1998) confirma que, apesar de discursos dando conta de um mundo "sem fronteiras", o Estado segue sendo um importante agente de "intervenção estratégica". Quanto ao investimento em infra-estrutura informacional, já em 1980 Somavía afirmava que a competência ao lidar com os processos informacionais poderia se constituir em fonte de poder "comparável aos grandes recursos naturais, tecnológicos e econômicos", nos processos econômicos.

Apesar da preocupação registrada com a posição competitiva do país, que reflete o aspecto externo e econômico da questão, os documentos do programa reconhecem que o fundamento da ação governamental deve ser o cidadão brasileiro e seu direito à informação. Segundo Jardim (1999), o direito à informação situa-se como um direito civil, um direito político e um direito social. O exercício de tal direito, entretanto, está condicionado às possibilidades de efetivo acesso e à capacidade de entendimento da informação, e são justamente a esses condicionantes que o Programa "Sociedade da Informação" pretende atender. É, para o Estado brasileiro, o momento de tomar decisões e implementá-las. 
Propiciar informação e educação a todos os cidadãos, entretanto, não significa tornar o Estado onipresente e determinador do destino das pessoas. Longe de mediar as relações entre os homens ou de guiá-los, cabe ao Estado prover, ou viabilizar que outros o façam, o acesso à informação. Quanto à capacitação, é dever do Estado assegurar a oferta de oportunidades educacionais para todos. O Estado, em sua atuação e a influência, não pode seguir os passos do despótico Leviathan, de Hobbes, e para isso a legislação existente e por construir e também o efetivo exercício da cidadania nos permitirão viver em um estado democrático, como preconizado por Locke.

A possibilidade de construção de um grande banco de dados com informações dos vários órgãos governamentais (Receita Federal, Previdência Social, fundos sociais etc.) pode representar ganhos de produtividade nas ações de governo, maximizando a alocação dos recursos. Por outro lado, evoca imagens como a do Big Brother, de Orwell, com a idéia de um controle quase total sobre os cidadãos. Essa preocupação é registrada por Somavía (1980), para quem a informação não pode se transformar em um "instrumento de dominação do governo sobre o resto da sociedade".

Esse receio está levando alguns países a renunciar, explicitamente, à construção de banco do dados do tipo, como é o caso do Canadá, que, ato contínuo à renúncia ao projeto, anunciou medidas para proteção da privacidade dos dados sob controle governamental (Wired News, 2000). Beniger (1986) também registra o receio de "despersonalização" dos indivíduos, que, no caso do Estados Unidos, vem recebendo críticas desde a Grande Depressão (década de 30), quando o governo americano chegou a empregar 26 milhões de pessoas e construiu grandes bancos de dados, com a tecnologia então disponível.

Dizard (1982) registra que, para os Estados Unidos, o fator mais relevante para o desenvolvimento foi a decisão de favorecer o ensino público gratuito há mais de 100 anos. No século XXI, o desenvolvimento terá como fator-chave o acesso universal à informação e aos produtos e serviços públicos, o que deverá fortalecer a cidadania e a solidariedade.

A questão da educação, sempre discutida e ainda à procura de um modelo que contemple as necessidades e os recursos do país, será o fator crítico em nosso caminho, como nação, e não como grupos, rumo à superestrada da informação. Em um esforço para instrumentalizar a escola pública, o governo federal, por meio do Programa Nacional da Informática na Educação (Proinfo), em parceria com as secretarias estaduais de educação, instalou 23.450 computadores em 2.276 escolas do país, até maio/2000, com previsão de 100 mil computadores até 2002 (Jornal do Brasil, 24.mai.2000).

Miranda (1977) afirma que a geração de conhecimento acontece via "canais do sistema educativo", por meio da transmissão da informação. Esses "canais" poderão ser incrementados a partir da própria infra-estrutura em construção, como pretende o Programa Sociedade da Informação. A educação será transformada, passando de uma experiência passiva e individual para um novo processo, "interativo e coletivo" (Sullivan-Trainor, 1995). Dizard (1982) também afirma que, na era pós-industrial, computadores e serviços de informação podem ser parte efetiva em um novo ciclo de aprendizagem.

O baixo índice de domicílios que têm computador gera um fosso digital entre os brasileiros, o que deve ser observado para evitar que os produtos e serviços das organizações públicas concentrem-se no ciberespaço e o atendimento convencional, ainda tão necessário, fique prejudicado. Mesmo assim, de acordo com a International Data Corporation (IDC), o número de computadores no Brasil em 2001 deverá chegar a 12 milhões, o triplo do que era em 1996 (Gurovitz, 1999), o que mostra um crescimento expressivo.

A preocupação com os deficientes físicos (Nielsen, 2000) e os analfabetos (inclusive os funcionais) deve ser considerada. É preciso assegurar a oportunidade de acesso à informação, por qualquer meio, inclusive a disponibilização de quiosques públicos de informação para o cidadão (Saur, 1997). De forma geral, os usuários não precisam entender os protocolos e programas que atuam enquanto eles realizam as operações de navegação e download de informações. Por isso, deve-se ter cuidado com as mensagens e avisos a serem exibidos.

Mais que as outras mídias, a Internet convida a um permanente processo de aprendizado e se integra, por seu dinamismo, às necessidades das organizações de promoverem um clima de colaboração e de intercâmbio de idéias e conhecimento, que caracterizam as organizações baseadas na informação e no conhecimento (Miranda, 1993).

Sobre a questão do aprendizado organizacional, Bemfica (1999) afirma que as organizações devem buscar referências em experiências de outras organizações. A prática do benchmarking, notadamente entre organizações públicas, que convivem com muitos problemas comuns (contingenciamentos orçamentários, restrições quanto a 
pessoal etc.), pode contribuir para a disseminação de soluções criativas e inovadoras na área pública.

As organizações públicas têm um papel fundamental na construção da chamada inteligência coletiva (Lévy, 2000). A divulgação e o uso de novos conhecimentos e tecnologias podem fortalecer o processo democrático, bem como possibilitar à sociedade encontrar novas formas de convivência e de superação dos desníveis existentes. A criação de conhecimento é uma das conquistas da sociedade prevista por Masuda (1982).

Nesse contexto, a participação do profissional de ciência da informação no processo de oferta de produtos e serviços mostra-se com uma crescente importância (Rosenfeld, 1998). Os cybrerians (termo usado por Rosenfeld para a nova geração de librarians) entendem que o novo terreno da Internet é uma nova fronteira, depois de muito tempo provendo acesso à informação impressa armazenada em bibliotecas tradicionais. Esse conhecimento acumulado, devidamente atualizado em termos tecnológicos, pode ser usado para resolver problemas de informação em inúmeros contextos (Barbosa, 1998).

Os profissionais da informação lidam, basicamente, com a organização e o acesso à informação por meio de sistemas. São habilitados para explorar tecnologias, o que vem ao encontro da afirmação de Dillon (2000) de que o gerente do projeto de desenvolvimento da oferta de produtos e serviços informacionais deve ter o conhecimento e a experiência em estruturas que contemplem os múltiplos níveis e camadas de interação entre pessoas, máquinas e tecnologias.

Em suma, o desafio a ser vencido é manter a simplicidade e, ao mesmo tempo, a funcionalidade, tendo sempre em vista que o interesse central é o atendimento das necessidades do cidadão, não a promoção da organização. É contribuir para a ampliação da participação nos processos decisórios do governo, para a compreensão dos processos econômicos, sociais e políticos, além de conflitos inerentes nos níveis nacional e internacional (Somavía, 1980). Malan (1980) também insistia na necessidade de ampliar os mecanismos de "controle da sociedade sobre o aparelho burocrático do Estado”. Castells (1998) afirma que a eficiência do Estado dependerá de sua capacidade de processar informação e de assegurar um processo decisório compartilhado: um "estado em rede".

Em 1977, Miranda afirmava que os países em desenvolvimento precisavam "acelerar a disseminação da informação em todos os níveis de sua estrutura social". É esse o desafio dos brasileiros a vencer no século XXI, para o desenvolvimento de uma sociedade que reflita o verdadeiro sentimento de brasilidade, que passa pelo amor à pátria, cultiva a fraternidade e condena a injustiça. Uma sociedade do tamanho do Brasil.

\section{"Ser informado é ser livre" (Norbert Wiener)}

\section{REFERÊNCIAS BIBLIOGRÁFICAS}

ANATEL (Brasília, DF). Uma proposta para o desenvolvimento da cidadania. [Brasília], 1999. $22 \mathrm{p}$.

BARBOSA, Ricardo Rodrigues. Perspectivas profissionais e educacionais em biblioteconomia e ciência da informação. Ciência da Informação, Brasília, v. 27, n. 1, p.53-60, jan./abr. 1998.

BEMFICA, Juliana do Couto; BORGES, Mônica Erichsen Nassif. Aprendizagem organizacional e informação. Ciência da Informação, Brasília, v. 28, n. 3, p. 233-240, set./dez. 1999.

BENIGER, James R. The control revolution. Cambridge : Harvard University, 1986. 493 p.

CARVALHO, Delgado de. História documental. Rio de Janeiro : Record, 1976. $356 \mathrm{p}$.

CASTELLS, Manuel. A sociedade em rede. São Paulo : Paz e Terra, 1999.

CASTELLS, Manuel. Hacia el estado red? In: SEMINÁRIO INTERNACIONAL SOCIEDADE E REFORMA DO ESTADO, 1998, São Paulo. [S. 1. : s. n.], 1998.16 p.

CONSELHO NACIONAL DE DESENVOLVIMENTO CIENTÍFICO E TECNOLÓGICO (Brasília, DF). Sociedade da Informação. Brasília, $1999.48 \mathrm{p}$.

CUNHA, Murilo Bastos da. Desafios na construção de uma biblioteca digital. Ciência da Informação. v. 28. n. 3. p. 257-268. set./dez. 1999.

DAVID, Rodrigo. A tradicional arquitetura de sites ainda é eficaz? Master forum. Disponível em: http:<www.ibestmasters.com.br/forum/ integra2504.asp > Acesso em: 1 jun. 2000.

DIGA lá e-business: a aposta num caminho sem volta. Revista Diga Lá, v. 4, n. 11, nov./dez. 1999.

DILLON, Andrew. Information architecture: why, what \& when? American Society for Information Science. Disponível em: http:<www.asis.org/Conferences/Summit2000/dillon>

DIZARD, Wilson P. The coming information age. New York : Longman, 1982.213p.

FLEMING, Jennifer. Web navigation: designing the user experience. [S. 1.] : O'reilly, 1998.

GUROVITZ, Hélio. Brasil digital. Revista Exame, São Paulo, 3 nov.1999.

INTERNET muda hábitos de leitura de notícias. Revista Eletrônica Surftrade Brasil. Disponível em: http:<www.surftrade.com.br/x/ artigo?cod= 200005098966> Acesso em: 31 maio 2000. 


\section{Henrique Flávio Rodrigues da Silveira}

JARDIM, José Maria. Entre o vital e o virtual: o acesso aos arquivos públicos no Brasil. [s. l. : s. n.], 1999. 14 p.

LÉVY, Pierre. Entrevista. Correio Braziliense, Brasília, 4 jun. 2000.

MALOFF, Joel. A Internet e valor da "internetização". Tradução de Rose Nânie Heringer da Silva. Internet World Magazine, July/Aug. 1996.

MARCHIONINI, Gary; KOMLODI, Anita. Design of interfaces for information seeking. Annual Review of Information Science and Tecnology, v. 33, 1998.

MASUDA, Yoneji. A sociedade da informação. Rio de Janeiro : Editora Rio, 1982.

MIRANDA, Antônio. Os conceitos de organização baseada na informação e no conhecimento e o desenvolvimento de serviços bibliotecários. Ciência da Informação, Brasília, v. 22, n.3, p. 227-232, set./dez. 1993.

MIRANDA, Antônio. Informação para o desenvolvimento. Rio de Janeiro : Livros Técnicos e Científicos, 1977. 135 p.

MONTEIRO, Elis. Jornal do Brasil, 11 maio 2000. Caderno Internet.

NEWSLETTER: revista eletrônica. Disponível em: http:<www.intermanagers.com.br $>$ Acesso em: 8 jun. 2000.

NIELSEN, Jakob. Designing web usability: the practice of simplicity. Indianapolis : New Riders Publishing, 2000.

NÓBREGA, Clemente. A quinta onda. Revista Você S. A., ago. 1999.

PEREIRA, Luiz Carlos Bresser. A Reforma do Estado dos anos 90: lógica e mecanismos de controle. Brasília : Ministério da Administração Federal e Reforma do Estado, 1997. 57 p.

PRADO JÚNIOR, Derly. Qual o melhor banco de dados para o seu site? Master forum. Disponível em: http:<www.ibestmasters.com.br/forum/ integra2305.asp> Acesso em: 1 jun. 2000.
C-BRASIL.com: the trade portal - uma rota de grandes conquistas. Revista do Serpro, p. 6-15, maio/jun. 2000.

ROSENFELD, Louis; MORVILLE, Peter. Information architecture for the World Wide Web. [S. 1.] : O'reilly, 1998.

SAUR, Ricardo Adolfo de Campos. A tecnologia da informação na reforma do Estado. Ciência da Informação, Brasília, v. 26, n. 1, p. 88-93, jan./abr. 1997.

SOMAVÍA, Juan. A estrutura transnacional de poder e a informação internacional. In: MATTA, Fernando Reyes. (Org.). A informaç̧ão na nova ordem internacional. Tradução de Paulo Kramer e Sigrid Sarti. Rio de Janeiro : Paz e Terra, 1980. p.31-52.

SOUZA, Carlos Fernando Mathias. A proteção autoral na chamada mídia eletrônica e duas brevíssimas palavras sobre o crime de informática. Brasília : Universidade de Brasília, 2000.

SULLIVAN-TRAINOR, Michael. Information superhighway. Tradução de Lenke Peres Alves de Araújo. São Paulo : Makron Books do Brasil, 1995. 289 p.

TARAPANOFF, Kira; ALVARES, Lillian. Cenários para serviços informacionais. Brasília: Thesaurus, 1994. 42 p.

TEIXEIRA, Cenidalva Miranda de Sousa; SCHIEL, Ulrich. A Internet e seu impacto nos processos de recuperação da informação. Ciência da Informação, Brasília, v. 26, n. 1, p. 65-71. jan./abr. 1997.

VALLE, André. Até que ponto a tecnologia pode trazer o sucesso para um Web site? Master forum. Disponível em: http:<www.ibestmasters.com.br/forum/integra0102.asp > Acesso em: 1 jun. 2000.

VICKERY, Brian; VICKERY, Alina. Information science in theory and practice. London : Bowker-Saur, 1989. 384 p.

WIRED NEWS. Revista Eletrônica. 30.5.2000. <www.wirednews.com.br> 